\title{
Stroke Rehabilitation Fact Sheet in Korea
}

\author{
Se Hee Jung, MD, PhD
}

Department of Rehabilitation Medicine, Seoul National University Boramae Medical Center, Seoul, Korea

\begin{abstract}
With rapid aging, the number of stroke survivors with disabilities in Korea is increasing even if mortality is declining. Despite coordinated efforts for quality improvement of stroke rehabilitation in Korea, the statistics of stroke rehabilitation were not well reported. This review aimed to provide contemporary and comprehensive statistics and recent changes in stroke rehabilitation in Korea. The Clinical Practice Guideline for Stroke Rehabilitation in Korea was developed in 2009 and updated in 2012 and 2016. Additionally, the representative databases for stroke rehabilitation include the Korean Brain Rehabilitation Database and the Korean Stroke Cohort for functioning and rehabilitation. These nationwide databases provided current information on stroke rehabilitation. Among Korean stroke survivors, one in three had motor impairment, one in four had cognitive impairment, one in three had speech impairment, one in four was dependent in ambulation, one in six had swallowing difficulty, and one in four was dependent in activities in daily living at 5 years after stroke. Comprehensive inpatient rehabilitation following transfer to the department of rehabilitation medicine significantly decreased stroke-related mortality and long-term disability. This review provides an improved understanding of stroke rehabilitation and guidance to implement timely, coordinated, evidence-based stroke rehabilitation services to relieve the socioeconomic burden of stroke.
\end{abstract}

Keywords Stroke, Rehabilitation, Statistics, Disability

\section{INTRODUCTION}

Stroke is the second-leading cause of death and the third-leading cause of death and disability combined based on the Global Burden of Diseases, Injuries, and Risk Factors Study (GBD) in 2019 [1]. Globally, the stroke incidence, stroke prevalence, deaths from stroke, and stroke-related disability-adjusted life-years (DALYs) increased by $70 \%, 85 \%, 43 \%$, and $32 \%$, respectively, from
1990 to $2019[1,2]$.

In Korea, one of the most rapidly aging countries, the absolute number of incident strokes increased by $29.7 \%$ from 2014 to 2019 [3]. However, stroke mortality decreased by $12.8 \%$ from 2014 to 2019 due to better risk factor management and improved medical interventions [3] (Fig. 1). In Korea, stroke is the fourth leading cause of death [3].

A previous study reported a socioeconomic burden of

Received January 22, 2022; Revised February 3, 2022; Accepted February 14, 2022; Published online February 28, 2022

Corresponding author: Se Hee Jung

Department of Rehabilitation Medicine, Seoul National University Boramae Medical Center, 20 Boramae-ro 5-gil, Dongjak-gu, Seoul 07061, Korea. Tel: +82-2-870-2672, Fax: +82-2-831-2826, E-mail: ideale1@snu.ac.kr ORCID: Se Hee Jung (https://orcid.org/0000-0002-0623-8752)

(c) This is an open-access article distributed under the terms of the Creative Commons Attribution Non-Commercial License (http://creativecommons.org/ licenses/by-nc/4.0) which permits unrestricted noncommercial use, distribution, and reproduction in any medium, provided the original work is properly cited. Copyright $\odot 2022$ by Korean Academy of Rehabilitation Medicine 
stroke in Korea as high as 4,135.78 billion Korean won in 2017, which has been increasing continuously [4]. More than 250,000 people are disabled due to brain disorders in Korea [3] and this population has also aged as the general population. Moreover, the medical cost of disabilities due to brain disorders is one of the highest among the 15 disability categories in Korea [5] (Fig. 2). Therefore, increased numbers of stroke survivors may impose a greater socioeconomic burden on the Korean society.

In Korea, stroke survivors with severe stroke and severe disability tend to stay hospitalized longer and experience repeated admissions to multiple hospitals [6]. Therefore, functional enhancement by implementing efficient stroke rehabilitation is needed to reduce the direct medical costs associated with stroke. While many factors affect

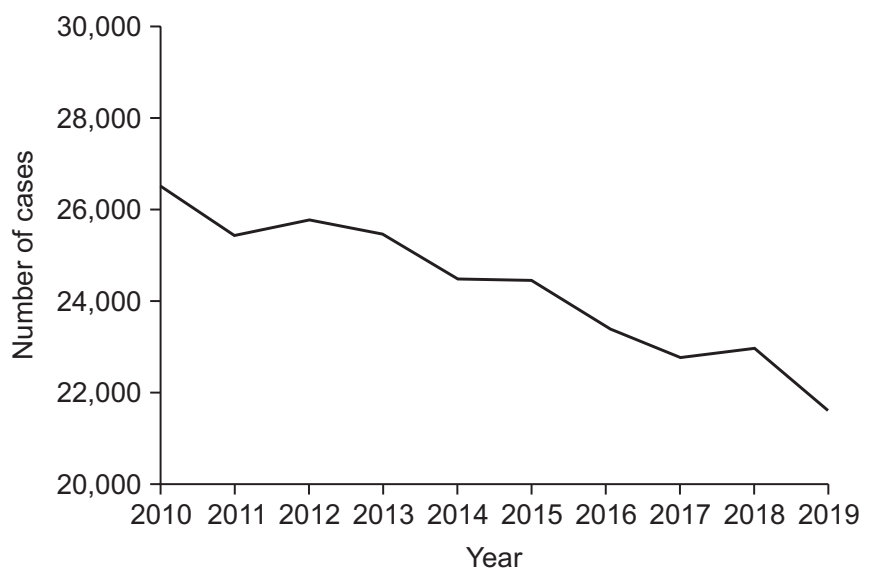

Fig. 1. Stroke mortality in Korea (2010-2019). post-stroke recovery, timely provision of appropriate rehabilitation services is critical for better functional recovery.

Both socioeconomic factors and the medical characteristics of the disease affect the organization of and changes to rehabilitation services. The socioeconomic factors include healthcare and the insurance system, the structure of medical reimbursement, healthcare resources, accessibility of medical services, social awareness, and medical care utilization behaviors of that society. Therefore, improved implementation of healthcare policies for stroke survivors requires an understanding of the current situation of stroke rehabilitation in Korea. The present review aimed to provide contemporary and comprehensive statistics and recent trends regarding stroke rehabilitation in Korea.

\section{COORDINATED EFFORTS TO IMPROVE THE OUALITY OF STROKE REHABILITATION IN KOREA}

\section{Improvement in acute stroke rehabilitation}

The Acute Stroke Quality Assessment Program (ASQAP) is an external audit that is used by the Health Insurance Review and Assessment Service (HIRA) in Korea to assess the quality of acute stroke care [7]. After the first assessment in 2005, the HIRA repeated stroke quality assessments in 2008, 2010, 2011, 2013, 2014, 2016, 2018, and 2021. The assessments include nine performance parameters and 15 monitoring parameters. The performance parameters include those related to early assessment for

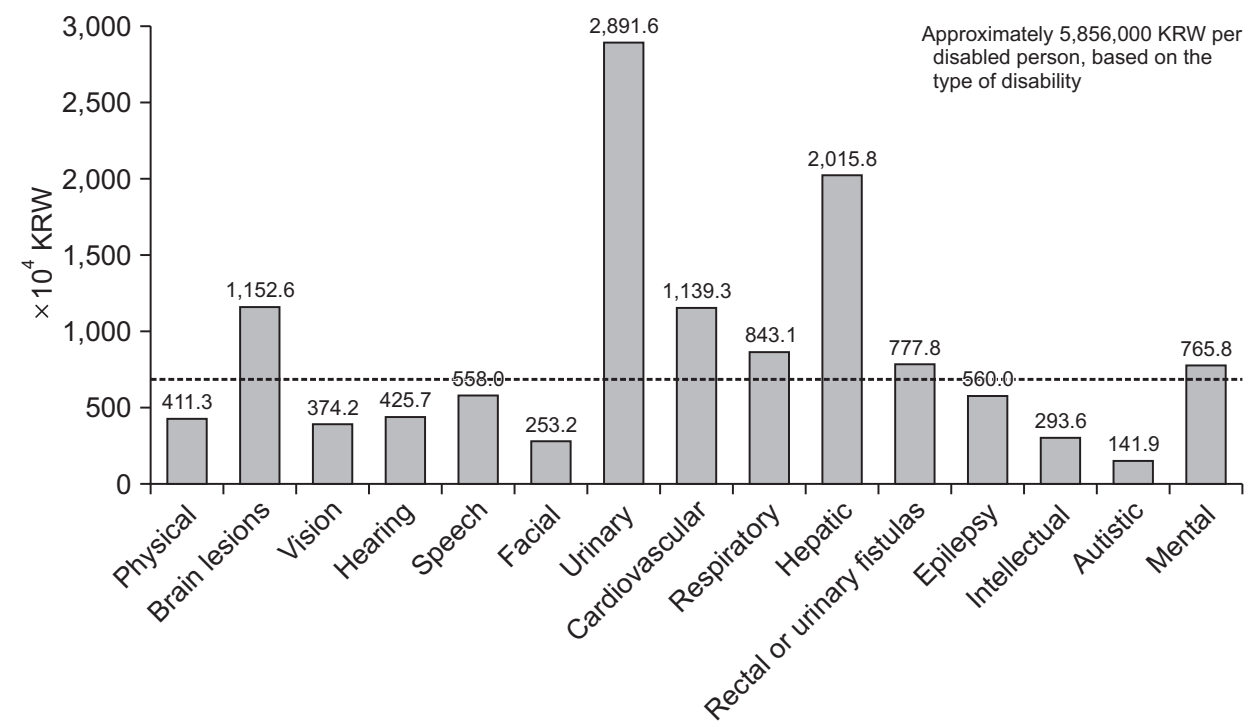

Fig. 2. Annual medical cost per person in 15 categories of disability in Korea (2018). Adapted from the National Rehabilitation Center [5]. KRW, Korean won. 
stroke rehabilitation and screening of swallowing function. The monitoring parameters include the provision of stroke unit care, early initiation of rehabilitation treatment, and functional outcome assessment at discharge. The ASQAP contributes to promoting the earlier initiation of stroke rehabilitation, improving the quality of acute stroke care, and reducing disparities among stroke hospitals in Korea.

\section{Clinical practice guideline for stroke rehabilitation}

Stroke rehabilitation specialists in Korea gathered and reviewed relevant literature to provide direction and standardization for the rehabilitation of acute, subacute, and chronic stroke in Korea. These efforts resulted in the development of the first edition of Clinical Practice Guideline (CPG) for Stroke Rehabilitation in Korea in 2009 [8]. These CPGs were updated in 2012 and 2016 as the second and third editions $[9,10]$. The CPGs for Stroke Rehabilitation in Korea provide evidence-based recommendations for higher-quality stroke rehabilitation, with timely, organized, and interprofessional care for the best predictable post-stroke recovery [9]. The development of these CPGs increases the likelihood of the delivery of a standard of care, with adequate resources and doses in comprehensive rehabilitation programs.

\section{Nationwide database for stroke rehabilitation}

Several nationwide databases for stroke rehabilitation exist in Korea. The Korean Brain Rehabilitation Database (KBRD) was developed in 2005 by the Korean Society of Neurorehabilitation (KSNR). The KBRD was an online system for the collection of nationwide demographic and clinical data from subjects with brain disorders including stroke, traumatic brain injury, and brain tumors [11].

The Korean Stroke Cohort for functioning and rehabilitation (KOSCO) is a large multicenter prospective cohort of people with acute first-ever stroke [2]. This cohort was constructed to prospectively investigate the long-term functional outcomes and quality of life issues arising in patients with first-ever stroke and to identify factors influencing residual disability and long-term quality of life [2].

The first KOSCO cohort enrolled 10,636 participants between August 2012 and December 2017 [2]. Among them, 7,858 subjects were longitudinally followed up for more than 60 months. The second cohort included 3,686 sub- jects enrolled between January 2020 and December 2020 . Among them, 2,431 participants have been followed up [12]. The inclusion criteria were as follows: (1) first-ever stroke (ischemic or hemorrhagic) with corresponding lesions on magnetic resonance imaging/angiography scan, (2) age $\geq 19$ years, and (3) an understanding of the purpose of the study and consent to participate in the study. The exclusion criteria were as follows: transient ischemic attack and recurrent stroke [2].

In this review, most data on stroke rehabilitation were derived from the two aforementioned databases.

\section{Stroke incidence, mortality, and recurrence in Korea}

The number of people who visited the emergency room due to stroke in $2019,120,584$, was a $31.1 \%$ increase compared to that in 2012 [3]. The number of deaths from stroke decreased from 26,514 in 2010 to 21,586 in 2019 [3] (Fig. 1).

Based on the analysis of the first KOSCO cohort, the cumulative death rates of the first-ever stroke were $11.8 \%$ at 1 year, $15.4 \%$ at 2 years, $18.9 \%$ at 3 years, $22.2 \%$ at 4 years, and $25.2 \%$ at 5 years post-stroke [12]. The significant factors related to mortality in first-ever stroke were the type of stroke, sex, age, comorbidities, hypertension, pneumonia, transfer to the Department of Rehabilitation Medicine (RM transfer), initial stroke severity, initial motor function, and initial ambulatory capacity [12] (Table 1). Stroke patients with RM transfer were more likely to survive $(\mathrm{p}<0.05)$ (Fig. 3$)$, while RM transfer and pneumonia were the only controllable factors related to poststroke mortality [12].

The analysis of the first KOSCO cohort showed recurrence rates of first-ever stroke of $8.9 \%$ at 1 year, $10.9 \%$ at 2 years, $12.7 \%$ at 3 years, $14.3 \%$ at 4 years, and $15.5 \%$ at 5 years post-stroke. Moreover, ischemic and severe strokes were more likely to recur than hemorrhagic and mild stroke [12]. Within 1 year after first-ever non-cardioembolic ischemic stroke, $6.0 \%$ of patients experienced a recurrence [13]. The predictors of recurrence were age, functional impairment at discharge, and comorbidities [13].

Functional change during 5 years after first-ever stroke

The first KOSCO cohort was followed up for more than 60 months [12] (Fig. 4). At 6 months post-stroke, $48.3 \%$ of patients showed motor impairment, $31.1 \%$ showed cog- 
Table 1. Multivariate analysis using Cox model for significant independent factors affecting mortality after firstever stroke

\begin{tabular}{lcc}
\hline \multicolumn{1}{c}{ Factors } & Hazard ratio & p-value \\
\hline Stroke type (infarction) & 0.637 & $<0.001^{*}$ \\
\hline Sex (female) & 0.794 & $0.001^{*}$ \\
Age ( $>65$ yr) & 4.045 & $<0.001^{*}$ \\
Comorbidity (CCAS $\geq 8$ ) & 0.480 & $<0.001^{*}$ \\
Hypertension & 1.160 & $0.028^{*}$ \\
Complication & 1.066 & 0.414 \\
\hline Pneumonia & 1.213 & 0.125 \\
Transfer or not to rehabilitation & 0.498 & $<0.001^{*}$ \\
$\quad$ medicine & & \\
NIHSS at 7 days & & \\
$\quad$ Moderate & 2.165 & $<0.001^{*}$ \\
$\quad$ Severe & 4.595 & $<0.001^{*}$ \\
FMA at 7 days (severe) & 0.879 & 0.207 \\
FAC at 7 days (severe) & 2.067 & $<0.001^{*}$ \\
\hline Adapted from Kang SH, Cho YJ & & \\
\hline
\end{tabular}

Adapted from Kang SH, Choi YJ, Lee KH, Kim YH, Jang WH, Shin MA, et al. The Korean Stroke Cohort for Functioning and Rehabilitation (KOSCO). Public Health Wkly Rep 2018;11:1152-62.

NIHSS, National Institutes of Health Stroke Scale; CCAS, Combined Condition- and Age-related Score; FMA, FuglMeyer Assessment; FAC, Functional Ambulatory Categories.

${ }^{*} \mathrm{p}<0.05$.

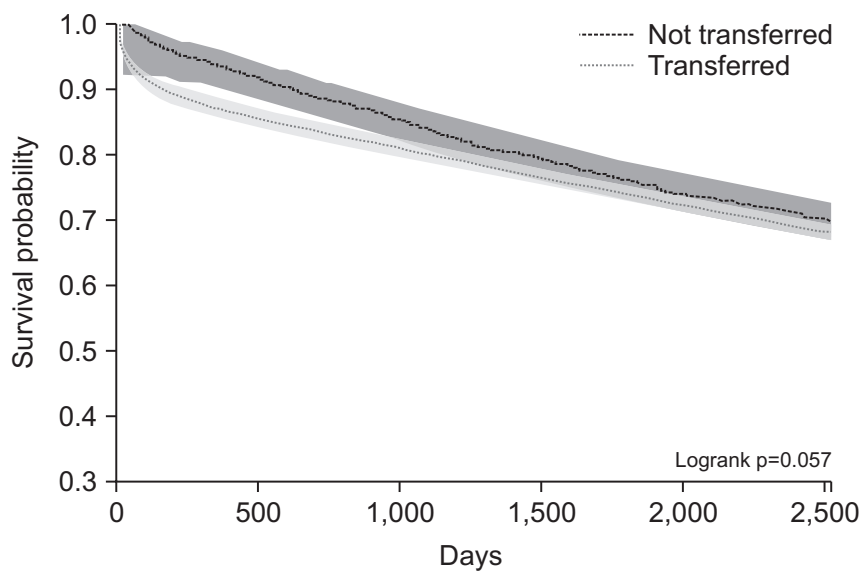

Fig. 3. Survival curve after first-ever stroke according to transfer to the Department of Rehabilitation Medicine. Adapted from the National Institute of Health [12].

nitive impairment, $46.5 \%$ had speech impairment, $18.1 \%$ had swallowing impairment, and $34.6 \%$ showed ambulation impairment. The prevalence of post-stroke depres- sion was $49.3 \%$ at 6 months. A total of $35.9 \%$ of stroke survivors remained dependent to some level in activities of daily living (ADLs) 6 months after stroke.

In each functional domain, significant improvement was observed up to 18 months after the first-ever stroke; however, functional deteriorations were observed in most domains starting in the third year. The functional decline at 3 years post-stroke was more evident in subjects who were $\geq 65$ years, subjects with more severe motor impairment within the first year, subjects with diabetes, or subjects with atrial fibrillation.

At 5 years post-stroke, $38.6 \%$ of patients showed motor impairment, $24.8 \%$ showed cognitive impairment, $36.6 \%$ had speech impairment, $16.0 \%$ had swallowing impairment, and $25.8 \%$ showed impairment in ambulation. The prevalence of post-stroke depression was $34.2 \%$ at 6 months post-stroke. A total of $24.4 \%$ of patients remained dependent to some level in ADLs 5 years after stroke.

As independence in ADLs at 3 months post-stroke continues to affect independence in ADLs until 5 years after stroke (Table 2), improvement in functional independence through comprehensive rehabilitation should be facilitated from the early phase after stroke.

\section{Recent changes in stroke characteristics and stroke rehabilitation}

In the KOSCO study, the second cohort was developed in 2020, 5-8 years after the first cohort. Therefore, comparisons of the two cohorts provide information regarding recent changes in stroke and stroke rehabilitation in Korea [12].

We observed no significant difference in the stroke type between the two cohorts. However, the mean age at the first-ever stroke increased by 1.9 years from the first to second cohort (Fig. 5). The number of persons who experienced a first-ever stroke in their 80s increased from $12.3 \%$ to $18.1 \%(\mathrm{p}<0.05)$.

The rates of admission to stroke units increased from $48.9 \%$ to $62.7 \%(\mathrm{p}<0.05)$; similarly, the referral to inpatient rehabilitation increased from $75.1 \%$ to $85.7 \%$ $(\mathrm{p}<0.05)$. The mean interval between admission and referral of inpatient rehabilitation decreased from 2.7 to 2.1 days.

Among rehabilitation therapies, bedside physiotherapy was most often provided to patients in the first KOSCO cohort before RM transfer (Table 3). In contrast, gait 
A K-MBI (ADL)

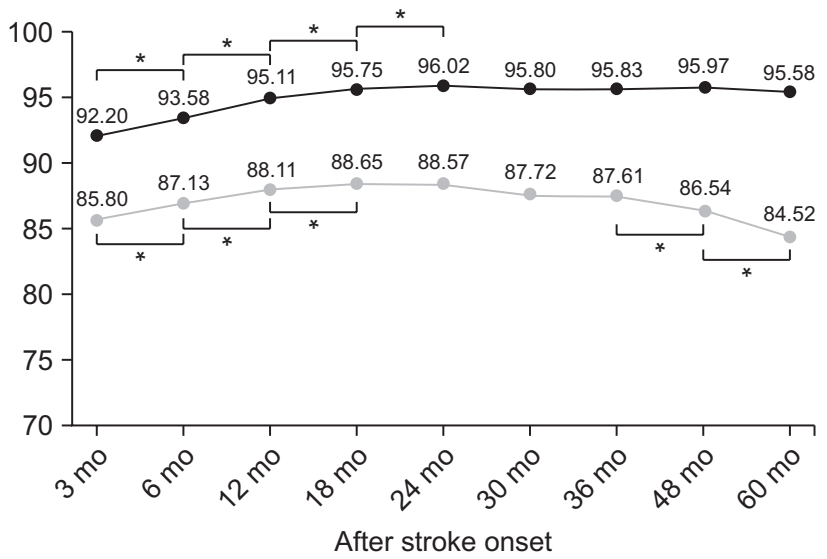

C K-MMSE (cognition)

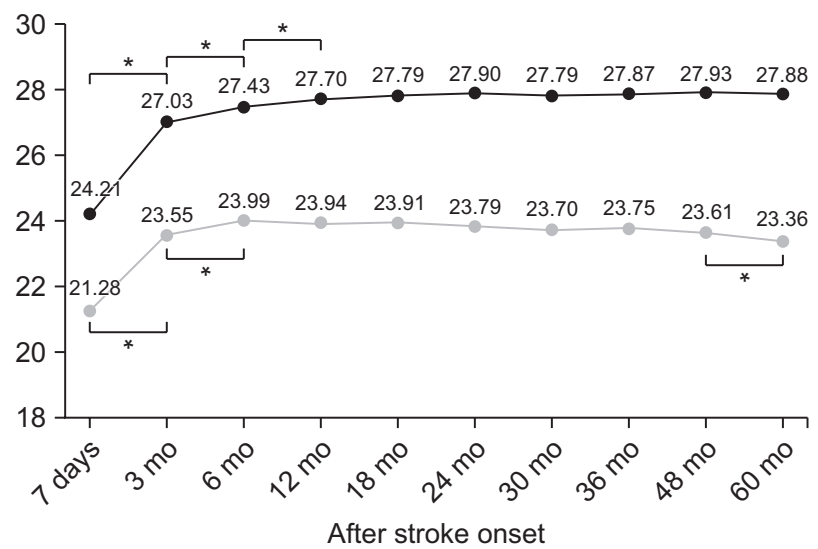

E ASHA-NOMS (swallowing)

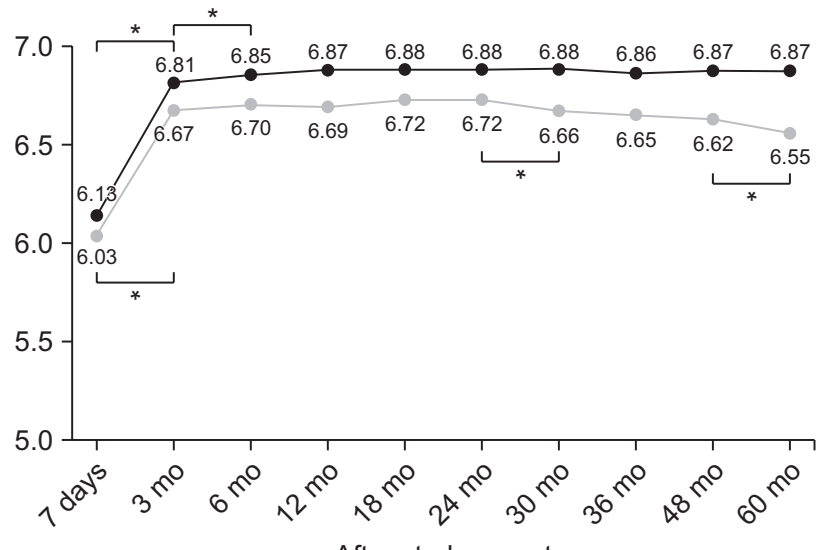

B FMA (motor recovery)

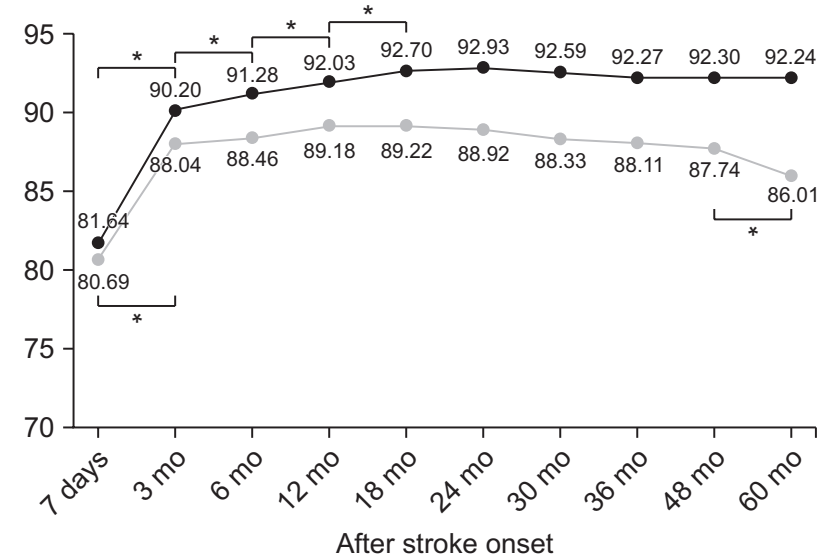

D FAC (ambulation)

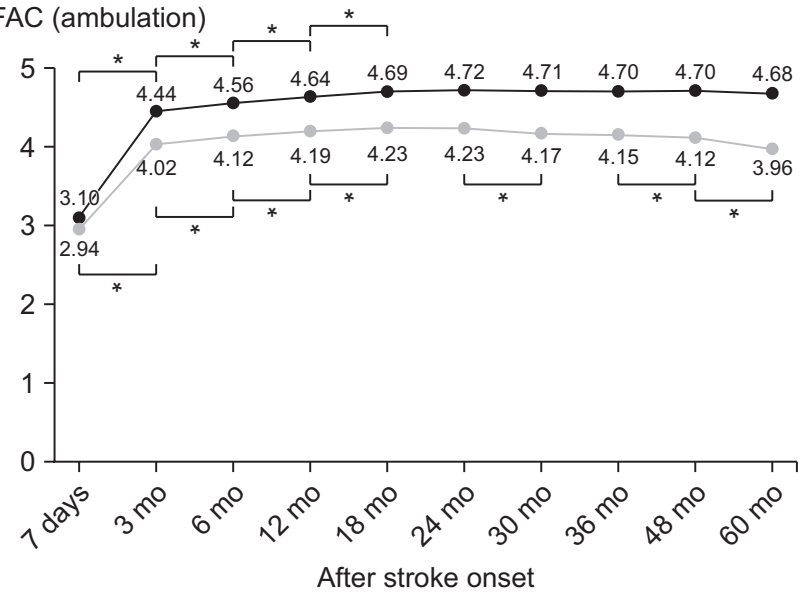

F Short K-FAST (speech)

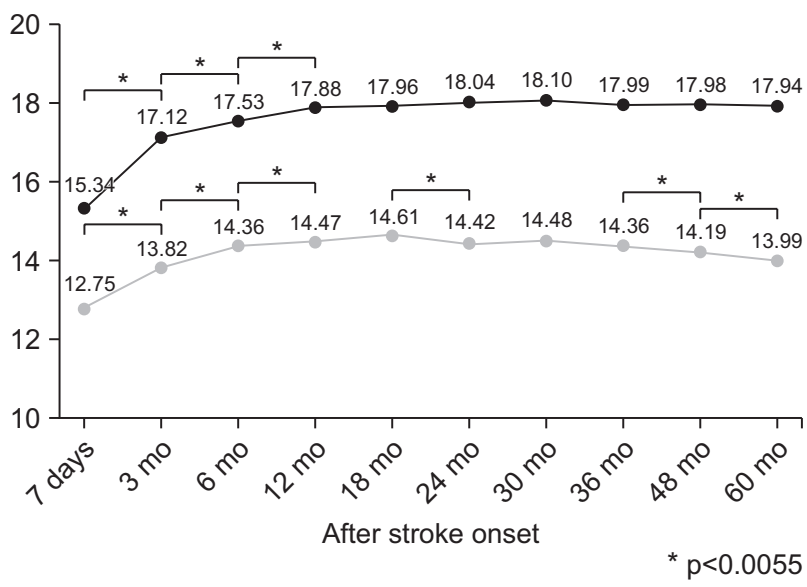

Fig. 4. Five-year post-stroke functional changes in the first cohort of the Korean Stroke Cohort for functioning and rehabilitation (KOSCO): (A) K-MBI (ADL), (B) FMA (motor recovery), (C) K-MMSE (cognition), (D) FAC (ambulation), (E) ASHA-NOMS (swallowing), (F) Short K-FAST (speech). Adapted from the National Institute of Health [12]. K-MBI, Korean version of Modified Barthel Index; ADL, activities of daily living; FMA, Fugl-Meyer Assessment; K-MMSE, Korean version of Mini-Mental State Examination; FAC, Functional Ambulation Category; ASHA-NOMS, Association National Outcome Measurement System Swallowing Scale; K-FAST, Korean version of Frenchay Aphasia Screening Test. 
Table 2. Significant predictors for independence in activities in daily living up to 5 years post-stroke

\begin{tabular}{|c|c|c|c|c|c|}
\hline Factors & $\begin{array}{c}6 \text { mo after } \\
\text { onset }\end{array}$ & $\begin{array}{c}1 \text { yr after } \\
\text { onset }\end{array}$ & $\begin{array}{c}2 \text { yr after } \\
\text { onset }\end{array}$ & $\begin{array}{c}3 \text { yr after } \\
\text { onset }\end{array}$ & $\begin{array}{c}5 \text { yr after } \\
\text { onset }\end{array}$ \\
\hline Age & $\mathrm{O}$ & & $\mathrm{O}$ & 0 & 0 \\
\hline Diabetes mellitus & 0 & $\bigcirc$ & & & \\
\hline Atrial fibrillation & O & & & $\bigcirc$ & \\
\hline Coronary artery disease & & & & O & \\
\hline Comorbidities before onset & O & & & $\bigcirc$ & \\
\hline Degree of disability before onset & & O & O & & \\
\hline Cognitive function 3 mo before onset & $\bigcirc$ & $\bigcirc$ & $\bigcirc$ & $\bigcirc$ & \\
\hline Motor function 3 mo before onset & $\bigcirc$ & $\bigcirc$ & $\bigcirc$ & $\bigcirc$ & $\bigcirc$ \\
\hline Ambulation 3 mo before onset & $\bigcirc$ & $\bigcirc$ & $\bigcirc$ & $\bigcirc$ & $\bigcirc$ \\
\hline Swallowing 3 mo before onset & O & $\bigcirc$ & O & $\bigcirc$ & $\bigcirc$ \\
\hline Speech 3 mo before onset & O & & $\bigcirc$ & $\bigcirc$ & $\bigcirc$ \\
\hline Activities of daily living & O & 0 & O & 0 & 0 \\
\hline
\end{tabular}

Adapted from the National Institute of Health [12].

Table 3. Rehabilitation therapies provided to the subjects in the first and second cohorts of the KOSCO before transfer to rehabilitation medicine

\begin{tabular}{lcc}
\hline & \multicolumn{2}{c}{ KOSCO cohort (\%) } \\
\cline { 2 - 3 } & \multicolumn{1}{c}{ First } & Second \\
\hline Physical therapy & 61.0 & 86.9 \\
Bed side PT & 37.8 & 76.7 \\
NDT & 40.9 & 91.3 \\
Mat/Gait & 6.2 & 4.9 \\
\hline Complex & 20.8 & 52.7 \\
FES & 2.8 & 0 \\
\hline Tilt table & & \\
\hline Occupational therapy & 27.4 & 46.8 \\
\hline Special & 11.2 & 25.7 \\
\hline Complex & 10.5 & 32.5 \\
\hline ADL & 3.2 & 10.1 \\
\hline Speech therapy & & \\
\hline Swallowing therapy & 1.2 & 1.4 \\
\hline Vital stimulation & 3.2 & 4.7 \\
\hline Oromotor & 0.5 & 1.3 \\
\hline Cognitive therapy & 1.8 & 0.5 \\
\hline Respiratory therapy & & \\
\hline
\end{tabular}

KOSCO, Korean Stroke Cohort for functioning and rehabilitation; NDT, neurodevelopmental treatment; ADL, activities of daily living.

training in the physical therapy room was the most frequent rehabilitation therapy provided to the second KOSCO cohort (Table 3 ). This change suggests the increasing

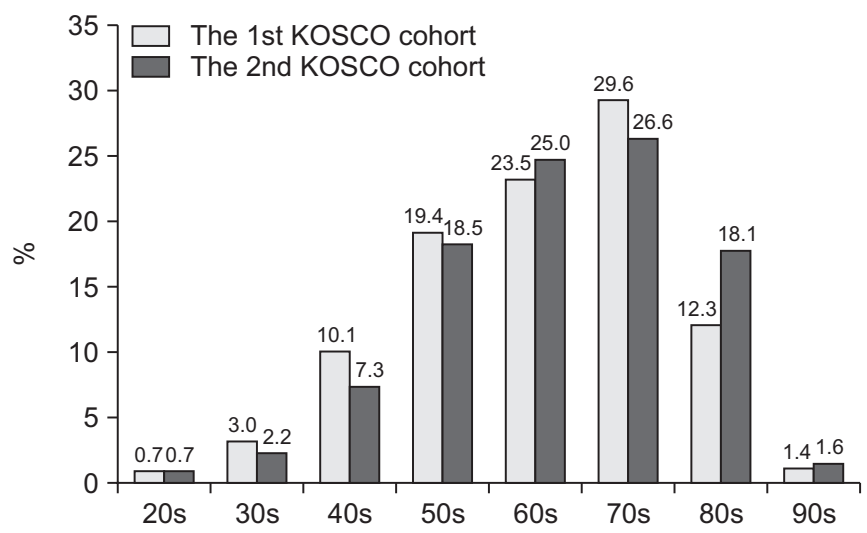

Fig. 5. Comparison of age distributions for first-ever stroke between the first and second cohorts of the Korean Stroke Cohort for functioning and rehabilitation (KOSCO). Adapted from the National Institute of Health [12].

prevalence of the early administration of comprehensive rehabilitation.

The rate of RM transfer increased from $16.5 \%$ to $19.7 \%$ $(\mathrm{p}<0.05)$. The number of days from stroke onset to $\mathrm{RM}$ transfer decreased from 16.8 days to 13.4 days $(\mathrm{p}<0.05)$. Considering a previous study of 5,212 patients from the KBRD, which reported a decrease in mean interval between stroke onset and RM transfer from 44 to 33 days between 2007 and 2011 [11], the delay incomprehensive inpatient rehabilitation has continuously shortened.

The mean length of stay (LOS) in the department of RM was 45 days in 2007 and decreased to 28 days in 2011 [11]. The mean LOS decreased from 32.8 days in the first 
KOSCO cohort to 25.7 days in the second KOSCO cohort $(\mathrm{p}<0.05)$.

The proportion of patients discharged from the department of RM increased from $16.4 \%$ to $18.7 \%$ ( $\mathrm{p}<0.05)$. Among discharge destinations, a higher proportion of stroke survivors was discharged to rehabilitation-specialized hospitals in the second KOSCO cohort (19.4\%) compared to the first KOSCO cohort $(12.4 \%, \mathrm{p}<0.05)$. However, this proportion was much lower than the $47.7 \%$ of patients who were discharged to another rehabilitationspecialized hospital between 2008 and 2009 [14]. Thus, more patients with stroke went home after comprehensive inpatient rehabilitation. The proportion of people discharged home also increased from $41.9 \%$ to $45.5 \%$ between the first and second KOSCO cohorts $(\mathrm{p}<0.05)$.

Functional status and quality of life at 3 months poststroke improved significantly in the second cohort $(p<0.05)$ and post-stroke depression was less prevalent in the second cohort compared to the first cohort $(\mathrm{p}<0.05)$.

\section{CONCLUSION}

This review focused on contemporary and comprehensive statistics and current changes in stroke rehabilitation in Korea. Despite its decreasing mortality, the socioeconomic burden of stroke has increased and will likely continue to do so without effective and efficient stroke rehabilitation strategies. Stroke rehabilitation is a comprehensive, multidisciplinary process with variable components, delivered by many professions as a continuum. Considering its regional and national specificity, knowledge of the current status of stroke rehabilitation is a prerequisite to maximizing its effectiveness and efficiency for better functional outcomes and reduced mortality. However, more nationwide database and research are necessary. This review and subsequent works will contribute to the inclusion in our society of future stroke survivors and their families, who will benefit from wellestablished stroke rehabilitation.

\section{CONFLICT OF INTEREST}

No potential conflict of interest relevant to this article was reported.

\section{ACKNOWLEDGMENTS}

I thank the researchers of the Korean Brain Rehabilitation Database (KBRD) and the Korean Stroke Cohort for functioning and rehabilitation (KOSCO).

\section{REFERENCES}

1. GBD 2019 Stroke Collaborators. Global, regional, and national burden of stroke and its risk factors, 19902019: a systematic analysis for the Global Burden of Disease Study 2019. Lancet Neurol 2021;20:795-820.

2. Chang WH, Sohn MK, Lee J, Kim DY, Lee SG, Shin YI, et al. Korean Stroke Cohort for functioning and rehabilitation (KOSCO): study rationale and protocol of a multi-centre prospective cohort study. BMC Neurol 2015;15:42.

3. Statistics Korea. Annual report on the causes of death statistics, 2019 [Online]. Daejeon, Korea: Statistics Korea; 2020 [cited $2022 \mathrm{Feb} 13$ ]. Available from: https:// www.kostat.go.kr/portal/korea/kor_nw/1/1/index. board?bmode=read\&aSeq=385219.

4. Lee YS, Lee HY, Leigh JH, Choi Y, Kim HK, Oh BM. The socioeconomic burden of acquired brain injury among the Korean patients over 20 years of age in 2015-2017: a prevalence-based approach. Brain Neurorehabil 2021;14:e22.

5. National Rehabilitation Center. 2018 Health statistics of people with disabilities [Internet]. Seoul, Korea: National Rehabilitation Center; 2020 [cited 2022 Feb 13]. Available from: http://www.nrc.go.kr/research/ board/boardView.do?no $=17751 \&$ fno $=37 \&$ depart no=\&menu_cd=05_02_00_01\&board_id=NRC_NOTICE_BOARD\&bn=newsView\&search_item $=\&$ search content=\&pageIndex $=1$.

6. Kim WS, Bae HJ, Lee HH, Shin HI. Status of rehabilitation after ischemic stroke: a Korean nationwide study. Ann Rehabil Med 2018;42:528-35.

7. Park HK, Kim SE, Cho YJ, Kim JY, Oh H, Kim BJ, et al. Quality of acute stroke care in Korea (2008-2014): retrospective analysis of the nationwide and nonselective data for quality of acute stroke care. Eur Stroke J 2019;4:337-46.

8. Kim YH, Han TR, Jung HY, Chun MH, Lee J, Kim DY, et al. Clinical practice guideline for stroke rehabilitation in Korea. Brain Neurorehabil 2009;2:1-38. 
9. Kim DY, Kim YH, Lee J, Chang WH, Kim MW, Pyun SB, et al. Clinical practice guideline for stroke rehabilitation in Korea 2016. Brain Neurorehabil 2017;10(Suppl 1):e11.

10. Rah UW, Kim YH, Ohn SH, Chun MH, Kim MW, Yoo WK, et al. Clinical practice guideline for stroke rehabilitation in Korea 2012. Brain Neurorehabil 2004;7(Suppl 1):S1-S75.

11. Joa KL, Han TR, Pyun SB, Rah UW, Park JH, Kim YH, et al. Inpatient stroke rehabilitation outcomes in Korea derived from the Korean Brain Rehabilitation Centers' online database system for the years 2007 to 2011. J Korean Med Sci 2015;30:644-50.
12. National Institute of Health. 10 year report of the stroke survival rate, functioning and rehabilitation in Korea. Cheongju, Korea: National Institute of Health; 2021.

13. Kim MS, Joo MC, Sohn MK, Lee J, Kim DY, Lee SG, et al. Impact of functional status on noncardioembolic ischemic stroke recurrence within 1 year: the Korean Stroke Cohort for functioning and rehabilitation study. J Clin Neurol 2019;15:54-61.

14. Chang WH, Shin YI, Lee SG, Oh GJ, Lim YS, Kim YH. Characteristics of inpatient care and rehabilitation for acute first-ever stroke patients. Yonsei Med J 2015;56:262-70. 